\title{
Team psychological formulation to create a shared understanding of distress: a qualitative study in an older people's mental health inpatient setting
}

\author{
Abi Tarran-Jones, S.J. Summers, Sarah Dexter-Smith and Sarah Craven-Staines
}

\begin{abstract}
Purpose - Team psychological formulation is an organisational intervention aimed at developing a shared understanding of a person's mental health difficulties. There is a lack of evidence regarding the therapeutic value of this approach for older people. The purpose of this paper is to explore how older people and their carers experience a cognitive-behavioural approach to team psychological formulation, within a mental health inpatient service in the UK.

Design/methodology/approach - A qualitative study using interpretative phenomenological analysis was undertaken. In total, 13 participants were interviewed: five older people/carer dyads, two lone older people and one lone carer.

Findings - Three overarching themes emerged: "Emotional impact of formulation" captured the mixed emotions that the process evoked in participants. "Making sense?" reflected the therapeutic value that participants experienced and what held them back from making gains in their recovery. "Disempowered people trapped in a biomedical world" illustrated the negative aspects of ward care, which hindered recovery. Research limitations/implications - The findings provide insights into the therapeutic value of team psychological formulation and the difficulties in facilitating the process effectively. More consistency is required to ensure that team formulation is standardised. Further research into the outcomes of the approach for older people is recommended.

Practical implications - Recommendations are proposed for how team psychological formulation can be conducted effectively, using the mnemonic "SETUP".

Originality/value - This study focussed on older people's and their carers' own perspectives regarding the team psychological formulation approach.
\end{abstract}

Keywords Mental health, Qualitative research, Older people, Team formulation,

Interpretative phenomenological analysis, Psychological formulation

Paper type Research paper

Introduction

As in many other developed countries, inpatient mental health care in the UK has received significant attention in recent years due to the lack of person-centred therapeutic approaches, poorer outcomes, and the lengthy periods that people spend in hospital (Mind, 2011; Schizophrenia Commission, 2012). Nearly a decade of financial austerity has further increased the pressure on staff and services, who work with individuals with progressively complex needs and presentations (Kerr et al., 2007). The quality of care within mental health services for older people has been highlighted as requiring significant improvements (Pinner et al., 2011). Research indicates that working with people with this level of complexity can lead to staff burn out, staff holding negative perceptions, staff disengaging from service users and ultimately poorer care (Kerr et al., 2007; Tai et al., 2009; Taylor and Sambrook, 2012).
Abi Tarran-Jones is based at Tees, Esk and Wear Valleys NHS Foundation Trust, Harrogate, UK.

S.J. Summers is based at the Teesside University, Middlesbrough, UK. Sarah Dexter-Smith is based at Tees, Esk and Wear Valleys NHS Foundation Trust, Harrogate, UK.

Sarah Craven-Staines is based at the Teesside University, Middlesbrough, UK.

Received 27 November 2018 Revised 1 May 2019 Accepted 30 May 2019 
Applied psychologists in the UK are increasingly working with organisations to develop staff knowledge and skills; to promote psychologically informed, recovery-oriented and person-centred mental health care (British Psychological Society, 2007; Department of Health, 2001, 2005). "Psychological formulation" is one such approach. It aims to summarise the psychological, biological and systemic factors that may cause or maintain a person's psychological distress (Division of Clinical Psychology, 2010). Using a scientist-practitioner approach, psychologists draw on theories and models to develop an understanding of a person's experiences, difficulties, strengths and resources. Hypotheses are proposed regarding the development and maintenance of problems, which are then tested by evaluating the impact of subsequent interventions. The aim is to develop an explanation that facilitates both decision-making and interventions; underpinned by psychological theory. A "reformulation" process ensures that formulations are further adapted in line with the changing needs of the person (Division of Clinical Psychology, 2011; Johnstone and Dallos, 2014). It has been argued that psychological formulation is an answer to the shortcomings of psychiatric diagnosis, which has been criticised for ignoring both social factors and personal meanings of distress (Johnstone, 2018). Psychological formulation also provides a non-expert stance, which pulls together information about an individual's resources and strengths.

Team approaches to psychological formulation (referred to hereafter as "team formulation") are used increasingly within mental healthcare settings in the UK and particularly in older people's services (Johnstone, 2018). Staff set time aside to think together, discuss and explore an individual's psychological difficulties, using a psychological formulation model. Despite the UK focus, the approach has international implications for mental health practitioners who develop case conceptualisations within treatment settings (Geach et al., 2018).

Team formulation may provide a safe space for staff to express feelings evoked by working with people with psychological difficulties and for these feelings to be contained and "detoxified" (Holmes, 2002; Summers, 2006). It may also minimise "splitting" within teams; improve team cohesion; reduce work-related stress and minimise burnout (Kerr et al., 2007). Team formulation can increase staff knowledge; develop shared care; increase multidisciplinary working and improve dissemination of information (Craven-Staines et al., 2010). Team formulation can inform selection and planning of psychologically informed interventions; guide systemic changes to care (Taylor and Sambrook, 2012; Moore and Drennan, 2013); and provide meaning and direction to nursing care (Crowe et al., 2008). Thus, the goals of team formulation are: to improve staff knowledge and skills; and to improve care experiences and outcomes (Holmes, 2002; Kerr et al., 2007).

Berry et al. (2016) investigated the effects of team formulation informed by a Cognitive Interpersonal Model, in an inpatient psychiatric rehabilitation setting. Service users were not involved in the formulation meetings. A single blind cluster randomized controlled trial design was adopted. Half of the wards were randomized to the intervention plus treatment as usual (TAU) or TAU only. Compared to TAU, service users who received the intervention felt less criticised by staff and also reported improvements in the ward atmosphere. Staff in the intervention arm reported less emotional distance from patients following the intervention, suggesting greater engagement with job roles. Within the context of this original study, Berry et al. (2017) used a qualitative approach to look at the narratives of staff and patients. The aims were to identify the effects of the intervention on practice, any active factors or variations in effectiveness, and any barriers or facilitators. A thematic analysis demonstrated improved staff understanding of patients, better team collaboration and increased staff awareness of their own emotions. Some key contextual factors were also identified, including overcoming both staff and patient anxiety, the importance of a collaborative rather than expert stance, dealing with competing demands and the centrality of management support.

In a study focussing on older people, Murphy et al. (2013) used thematic analysis to explore the views of nurses regarding psychological formulation, using a team approach, within an older people's mental health inpatient service. The formulation approach was based on a model developed by Dexter-Smith (2007). A three day training package for staff regarding the approach was followed by weekly formulation sessions with staff, led by a Clinical Psychologist. The findings were consistent with those of other team formulation studies, suggesting that the approach increases staff understanding of service-users, helps staff tolerate difficult feelings and 
improves team working (Summers, 2006; Berry et al., 2016, 2017). The findings further suggested that team formulation can lead to modification of care for individuals and enable teams to develop a unified and consistent approach to care. The authors utilised Prochaska and DiClemente's Transtheoretical Model of Change (1986; as cited in Murphy et al., 2013) to understand the process of staff applying psychological knowledge to clinical practice. It was suggested that prior to psychological consultation staff were in the "precontemplative stage" as they were unsure of the value of psychology. Through increased visibility of psychology on the ward, staff moved in to the "contemplative stage", and involving staff in formulations led to them into the "action stage". The authors also highlighted some barriers to staff translating the knowledge and skills learned through formulation into clinical practice. These included staff shortages, staff reporting they had limited time outside of formulation meetings to implement changes, and staff prioritising task-focussed activities over formulation. The study provides some optimism regarding the practical application of formulation within the evidence-base. This study focusses on exploring the topic from staff perspectives only, limiting the validity of the findings.

In their recent systematic review of team formulation, Geach et al. (2018) identified three instantiations of team formulation: sharing ideas informally, reflective practice meetings and formulation focussed consultation. Development of a shared understanding was found to be a common focus of the approach. However, the authors argued that research regarding team formulation is hindered by a lack of specification and standardisation of the approach.

Given the lack of focus in research regarding team formulation with older people, particularly regarding older people's and their carers' views, the current study aimed to explore how older people with mental health problems, and their carers, experience team formulation within a mental health inpatient service. Care was taken to ensure that the approach to team formulation was well defined and understood by those involved. This was deemed important as formulation is used by both psychiatrists and psychologists and there can be some differences in how the approach is understood and operationalised (Hughes, 2016; Mohtashemi et al., 2016; Baird et al., 2017).

\section{Methods}

\section{The team formulation approach}

The team formulation approach used the Problem Focussed Psychological Formulation Model (Figure 1), a revised version of a cognitive-behavioural approach developed within a UK NHS older people's inpatient setting, to help staff incorporate information regarding the older person from the multidisciplinary team (Dexter-Smith, 2010). More of a focus was provided on relational aspects, in addition to underlying unmet and recovery needs, drawing from Maslow's (1943) hierarchy of human needs; person-centred care as detailed by Kitwood (1997); and the CHIME framework: connectedness, hope and optimism about the future, identity, meaning in life and empowerment (Leamy et al. , 2011). The team formulation results in an intervention plan. Each of the four wards involved in the study used this approach, conducted as a standalone event. As shown in Table I, there were variations in how the team formulation was timed, and who was involved. The study was approved by both University and NHS ethics committees.

\section{Design}

Due to the lack of relevant research literature regarding team formulation with older people, a qualitative method was deemed appropriate to gain a deep understanding from the participants' own perspectives. Previous research has tended to focus on staff perspectives. Interpretative phenomenological analysis (IPA); (Smith et al., 2009) was deemed the most appropriate qualitative method. IPA is concerned with understanding individuals' lived experiences of important events and how they make sense of these. The aim is to provide a co-construction between the participant and the researcher, rather than a true first-person account on behalf of the participant. This approach is widely used within applied psychological research (Larkin et al., 2006) and has been used with older adults to capture, for example, subjective experiences of dementia (Godwin and Poland, 2015). 
What is "live" to me at the moment?-Provide two or three key issues: physical/cognitive/social/occupational/environmental

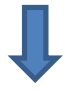

My earlier life history that might relate to the issues above

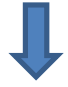

How I, and others, describe me

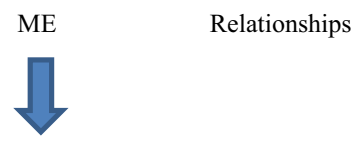

Day to day situations/events that cause distress

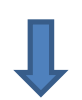

Thoughts/what I say

What others do or say that is unhelpful

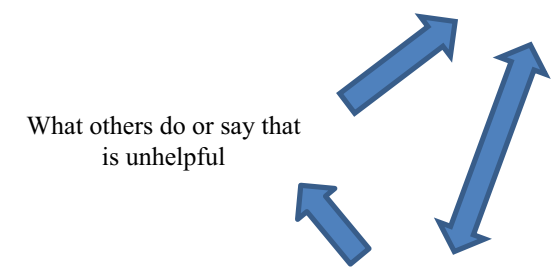

Behaviour/what I do

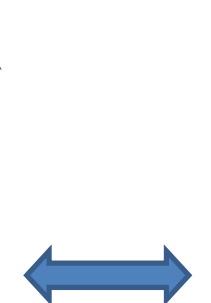

Summary of formulation

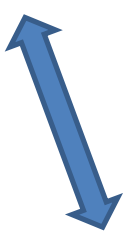

Emotions/how I appear

Strengths and resources

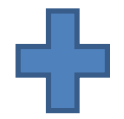

Recovery goals, needs Aims

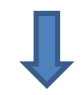

Intervention plan

Team formulation was explored from the different perspectives of older people with mental health difficulties, and their carers. Shenton (2004) argued that different views of a particular event enables cross-comparison of cases and the opportunity to verify different participant viewpoints.

\section{Participants}

The study took place in one region in the North of the UK. The older people were receiving treatment in a NHS older people's functional mental health inpatient service and were receiving treatment for a range of complex and often co-morbid mental health problems, including anxiety, depression, personality disorders and psychosis. Participants presented with high risk behaviours such as self-harm, suicidal ideation and behaviour and personal neglect. 
Table I Participant characteristics and team formulation variations

\begin{tabular}{|c|c|c|c|c|c|c|}
\hline $\begin{array}{l}\text { Interview number } \\
\text { identifier }\end{array}$ & $\begin{array}{l}\text { Participant involved (Older } \\
\text { Person }=O P ; C=\text { Carer) }\end{array}$ & Gender & $\begin{array}{l}\text { Age } \\
\text { range }\end{array}$ & $\begin{array}{l}\text { Carer's relationship with } \\
\text { older person }\end{array}$ & $\begin{array}{l}\text { Timing of team } \\
\text { formulation }\end{array}$ & $\begin{array}{l}\text { Who was involved in the team } \\
\text { formulation }\end{array}$ \\
\hline \multirow[t]{2}{*}{1} & OP & Male & $65-70$ & Spouse & Mid stay & Psychologist only \\
\hline & $\mathrm{C}$ & Female & $65-70$ & & & \\
\hline \multirow[t]{2}{*}{2} & $\mathrm{OP}$ & Male & $65-70$ & Brother-in-law & Admission & Psychologist and Psychiatrist \\
\hline & $\mathrm{C}$ & Male & $65-70$ & & & \\
\hline \multirow[t]{2}{*}{3} & OP & Female & $75-80$ & Spouse & Mid stay & Psychologist only \\
\hline & $\mathrm{C}$ & Male & $75-80$ & & & \\
\hline 4 & $\mathrm{OP}$ & Female & $65-70$ & $\mathrm{n} / \mathrm{a}$ & Discharge & Small group \\
\hline 5 & $\mathrm{OP}$ & Male & $65-70$ & $\mathrm{n} / \mathrm{a}$ & Discharge & Large group \\
\hline \multirow[t]{2}{*}{6} & OP & Female & $75-80$ & Son & Discharge & Small group \\
\hline & $\mathrm{C}$ & Male & $50-55$ & & & \\
\hline
\end{tabular}

In IPA, a homogenous sample is sought so that psychological similarities and differences are analysed within a group that is similar according to important variables (Pietkiewicz and Smith, 2014). Purposive sampling was therefore used to recruit participants, in that participants were selected on the basis that they had experienced team formulation. The older people were initially approached by a clinical psychologist, on a sequential basis, as team formulations occurred. With their consent, they were then contacted by the researcher (AT-J) and an interview was arranged with the researcher between one and four weeks following the team formulation. These participants self-selected their carer participants on the basis that the carer was actively supporting them through their recovery (family members or friends rather than paid care workers).

The purpose of IPA is to extract rich and detailed data from a small number of participants, to enable an in-depth analysis within and across cases. Unlike other qualitative methods, data saturation is not a goal in IPA research. IPA has a commitment to idiography, and, as such, a small sample size is preferable. A mean sample size of 15 participants in IPA studies has been reported (Reid et al., 2005). In total, 13 participants: five older people/carer dyads, two lone older people, and one lone carer, took part in the study (Table I). The older people were over 65 years old; there was no upper age limit. There were no age restrictions for carer participants. All participants were required to have capacity to consent, to be resilient enough to engage in the research, and to speak fluent English to enable them to participate fully in the research interview.

\section{Data collection}

Semi-structured interviews were conducted with participants to facilitate an in-depth understanding of their lived experiences of team formulation. The semi-structured interview schedule served as a loose guide to the conversation to allow participants to tell their stories and to minimise the impact of the researcher's own biases on the discussion (Smith et al., 2009). Open-ended questions were used to encourage rich answers. Neutral prompting questions were designed to elicit participants' feelings and thoughts, and to probe deeper into the essential features of their experiences (Smith et al., 2009). The interview schedule was revised following conversations with service-users (who were inpatients on the wards involved) and their carers; all of whom had experienced team formulation. The schedule was then refined following submission for ethical approval by University and NHS Research Ethics Committees. The schedule outlined eight broad questions:

1. In your own words, what was the purpose of the formulation meeting?

2. What was your experience of the formulation meeting?

3. How has the formulation impacted on (older person's name) experience of being on the ward?

4. What was agreed would be the best way forward for your care after the meeting? Did what was agreed match what had been discussed in the meeting? 
5. Did you experience a difference in the care you received, or how people treated you, after the meeting?

6. Do you think that people who were not in the meeting also understood what had been agreed?

7. In what ways has the care that (older person's name) has received following the meeting impacted on you both and on (older person's name's) recovery?

8. What is your understanding of the cause of these (aforementioned in question 7) changes?

The interviews ranged in length from 35 to $80 \mathrm{~min}$ and ended at the point where participants felt they had no more to say on the topic, or when the researcher believed all questions had been answered. Interviews were audio-recorded and the researcher transcribed each recording verbatim to promote familiarity with the data, acknowledging that transcription is a form of interpretation in itself (Smith et al., 2009).

A number of factors determine a study's sensitivity to context or credibility. The influence of power dynamics within mental health care settings and clinically related research is inherent (Yardley, 2000) and may affect the willingness and ability of participants to be honest in their experiential accounts (Shenton, 2004). Measures were taken to foster participants' confidence in the researcher and openness and honesty in their responses. A pre-interview meeting and preamble to each interview were conducted, to help develop a rapport between the researcher and the participants. Interview questions were designed to progress from the concrete to the analytical, to orientate participants to the research interview.

Participants were reminded of their right to withdraw from the study or stop the interview if they needed to. The researcher's neutral and non-judgemental standpoint was highlighted to participants and they were reassured that their responses would not impact on their care or be feedback to the care team.

\section{Data analysis}

The data were analysed by the researcher according to the six stages of IPA outlined by Smith et al. (2009): reading and re-reading; initial noting; developing emergent themes; searching for connections across emergent themes; moving to the next case; and looking for patterns across cases. First, the transcripts were read and re-read in detail. A reflective journal was kept throughout to facilitate reflection on any factors that may have impacted on data analysis, with the aim of "bracketing-off" the researcher's expectations, assumptions and beliefs, ensuring that the participant was at the centre of the analysis. In stage 2, a line-by-line analysis of each transcript occurred, with annotations made in the margin with some exploratory comments. In stage 3 , each transcript was linked with the researcher's exploratory comments, marking the beginning of the collaborative interpretation of the participant's experiences. The aim here was to turn the exploratory comments into themes, which were annotated on the opposite margin to the exploratory comments. In stage 4, the chronological emergent themes were re-ordered and categorised, for example, into similar groups or polar opposites. Stage 5 involved analysing the next participant's experiential account according to the previous steps. Finally, in stage 6, any similarities, links and differences between themes were noted. Superordinate (over-arching) themes were developed from the emergent themes.

One supervisor engaged in a process of triangulation through the analysis of three transcripts, selected at random, in as much detail as the researcher had. The purpose of this was to verify the themes that had been identified, question inferences and provide alternative perspectives (Smith et al., 2009). Agreement was reached regarding the "emotional impact of team formulation" and "making sense?" superordinate themes. With regards the third superordinate theme, "disempowered people trapped in a biomedical world", the researcher had more difficulty structuring and capturing this effectively, particularly as these experiences had not been the focus of the interviews. Despite this, participants seemed compelled to share their narratives regarding the degrading and controlling nature of the ward procedures and it became clear that it was important to capture these experiences. The resultant theme was developed and refined through discussion and agreement in triangulation meetings. 
Participants were invited to check initial themes from the data analysis to ensure they agreed with the researcher's interpretation of their account. Three participants took up this invitation, and subsequently agreed that the analysis had accurately and aptly captured their experiences.

\section{Results}

Smith et al. (2009) proposed that in samples of six or over, superordinate themes are conceptually sound if half or more of the participants' accounts contribute to the theme. This was true for all the superordinate themes that emerged from the data. Three superordinate themes, with associated sub-themes, emerged (Figure 2).

\section{Emotional impact of team formulation}

This captured participants' varied and contrasting emotional responses to the experience of team formulation and the impact of facing the reality of their life circumstances. In addition, whilst the model of team formulation was applied consistently, there were some differences in the process (Table I), which led to differing emotional responses. For approximately half of the participants, the team formulation felt safe and enabled them to have a voice; whereas others felt exposed and silenced. In addition, a small number of participants' emotional reactions to team formulation were dynamic and changed over time. There were three sub-themes, as detailed next.

Positive emotional impact. Some participants reported experiencing positive emotions, such as hope and a sense of feeling valued and listened to; and linked this to the helpful way in which the team formulation was facilitated. A round table layout and the curious questioning approach of the psychologist were detailed as helpful factors:

[...] we were sat round a table, and know it sounds silly, but it's more relaxing in that kind of way [...] (OP4).

[...] and having (name of Clinical Psychologist) say, as he was going through: "Well hold on a minute let's have a closer look at that, let's have a closer look at that, if that's OK with you [...]." And that, that kind of gave me permission in a way, to identify what "that" was (OP1).

Negative emotional impact. In contrast, some participants spoke about experiencing negative emotions during the team formulation; including tiredness, fear, vulnerability and exposure. Participants linked this to the large group format and the high number of professionals involved in the process:

[...] I was in a courtroom [...] I was defending myself and they were a load of prosecutors, if you've ever been in a courtroom (OP5).

Dynamic emotional reactions. This captured the dynamic nature of some participants' emotional response to the process. Whilst team formulation was initially difficult, this then evolved into a more positive experience:

[...] suddenly it just all came together and this emotion came out, actually (name of Psychologist) was very pleased about it [...] she could see that I was actually underneath very, very sad about so many things and that I hadn't been showing the emotion, and to her this was a very good sign (OP5).

Figure 2 Subordinate (bold) and sub-themes (dot points)

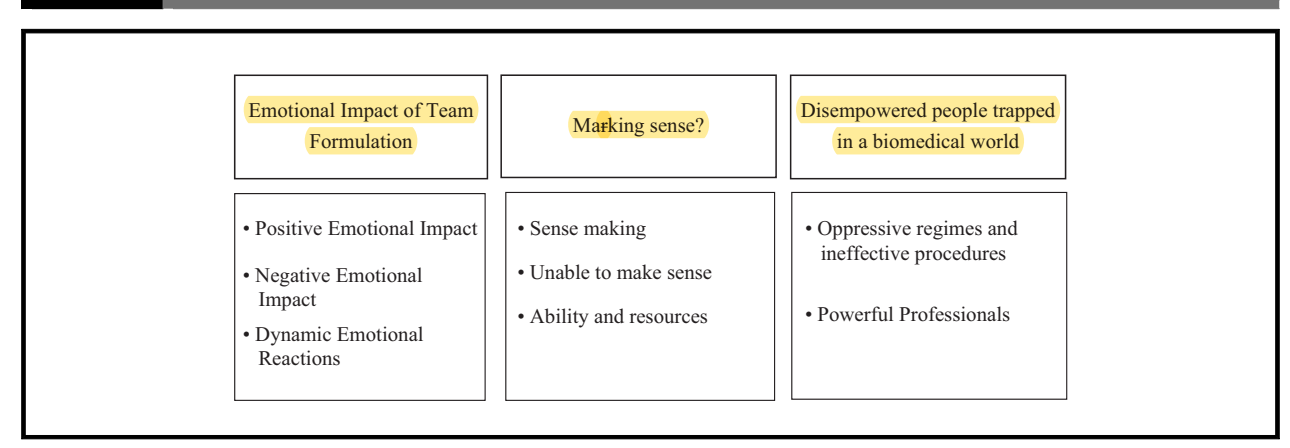


Others specifically discussed the therapeutic gains, in that the process helped them identify ways to effect personal change:

It was almost an awakening, you know, wasn't it? [...] And it was almost as if (name of Psychologist) actually awakened all these feelings in both of us, that there was a way forward. [...] You know we weren't so lost [...] (C1).

\section{Making sense?}

Team formulation enabled most participants to make sense of the psychological difficulties: a positive and empowering experience. However, it was apparent that something held some back from taking a fully active role in recovery, hence this theme being posed as a question. There were four sub-themes.

Sense making. Some participants reported that the process helped them make sense of their emotional experiences, offered new perspectives and facilitated a sense of validation:

[...] it provides a framework that just hasn't been there before [...] (OP1).

Others spoke about a collaborative sense-making process and improved contact with family and professionals:

[...] I think that my family have got a greater awareness of how I'm feeling. I've found that since l've been home l've had more contact with my daughter [...] (OP4).

[...] the doctors were trying to explain and the way they were trying to explain it [...] it was good. We were as I would say: "living on the darkside", weren't we? And when we had this meeting it was all fetched into, into the middle, between doctors and relations (C2).

Unable to make any sense. A few participants appeared to make less sense of the team formulation process, which either generated only a basic understanding of the difficulties, or confusion:

[...] knowing the basics, cos that's all that came out of the meeting, the basics, skimmed across the waves and just got a few bits about why my mum's like she is [...] (C8).

It's very difficult to say what my emotions were, puzzlement as much of anything (OP3).

Some participants expressed reservations about the usefulness of team formulation:

Well even at the end I thought: "What am I supposed to do now? What, how has that plan helped me?" (C7).

[...] formulation plan never discussed, never asked about. It just seemed to me to be a waste [...] (OP1).

The poor timing of the team formulation was also mentioned as a key factor:

I just wished we'd had it at the beginning [...] because it felt like they didn't know mum at all (C7).

These views indicate that certain factors (e.g. timeliness and stage in recovery) may need to be considered to promote service-users' and carer's ability to engage in the process.

Ability and resources. There was evidence of some common personal characteristics and resources in participants that facilitated learning from the process of team formulation and their capacity to engage meaningfully with it. Some reflected on the benefit of prior work experience in helping them understand the process:

Even I didn't understand everything. But I'm not really sure if someone from the outside (health care) [...] could of understood that really (C7).

\section{Disempowered people trapped in a biomedical world}

Some participants perceived team formulation to have little or no impact on their care. For these older people and carers, whilst ward care practices were not a direct focus of the interviews, there were some significant negative experiences that "loomed large" in their narratives. There were two subordinate themes. 
Oppressive regimes and ineffective procedures. This centred on the lack of liberty and selfagency that some participants experienced. These participants described how staff time was taken up with tasks, rather than interactions with patients on the ward. Ineffective staff communication was also highlighted:

[...] I couldn't see the reason why I had to have my toiletries and my clothes locked up. That felt as though I was in a prison in some way. But they were restored to me after a while, and I did get a key to my room. That improved things for me, but I just got to the point sometimes where I thought: "Well just let them do what they want because I am not going to be here forever, I will eventually be going home" (OP4).

I was really frightened to talk to anybody, I didn't know what to say that was acceptable (OP3).

Powerful professionals. Some participants expressed a sense of powerlessness when voicing their concerns and an inability to feedback regarding their care. Some reflected negatively on the staff approach. Others found it difficult to challenge professionals or to comment on the care that was provided, and implied that professionals assumed an expert position and the family assumed a passive role:

[...] the senior members of staff, nursing staff, are almost invariably taken up [...] with medicating, medicating, medicating [...] to try to get time with them is really quite difficult [...] it's a very depersonalising experience [...] (OP1).

I just felt that we just got her in hospital and we couldn't get her out. They were just giving her pills all the time and that's how I always felt. And as time went on she was getting more and more zombie-ish, dribbling, shaking and then they sent her home like it, I didn't agree with it (C8).

\section{Discussion}

This study aimed to explore how older people with mental health problems and their carers experience team formulation within an inpatient service. The study provides insights into how team formulation can serve to promote recovery, and how practices may act as a barrier to recovery.

Participants who reported positive responses to team formulation related these to the approach of the psychologist and the meeting itself, and the facilitation of a belief that things could be different. The therapeutic relationship can be key in formulation, bringing about positive changes in therapy (Rayner et al., 2011; Redhead et al., 2015). It is possible that these factors may also be at play in team formulation.

Despite their initial distress, some participants found team formulation helpful in making sense and identifying meaning. It enabled them to tell their story and to gain a new perspective. The approach also assisted some participants with their relationships with others. This replicates previous findings within the psychotherapy literature: that formulation enables individuals to talk more openly about their experiences with others (Redhead et al., 2015). Some participants were empowered by team formulation and were able to rebuild their sense of self-agency and self-determination, both of which are fundamental tenets of recovery (Onken et al., 2007).

Some found the group format of team formulation intimidating and exposing, questioning the way in which the process was organised. Others found it difficult to engage in the intervention and the recommendations that followed. One could hypothesise that transferring conversations about psychological understanding from the individual and containing environment of psychotherapy, to the unpredictable and indiscrete environment of team formulation, may cause individuals distress. This may in turn limit the therapeutic value of this approach. It was notable that serviceusers who demonstrated a greater ability to self-reflect and articulate their emotional experiences reported more favourable emotional experiences of formulation and greater therapeutic gains. These factors may reflect individual differences related to age, education and cultural background, each of which is likely to impact on whether service users and carers can actively and meaningfully engage in team formulation.

Ward care "loomed large" in the narratives, despite not directly being the focus of the interviews. Some spoke about oppressive regimes and rules. They felt silenced from having a voice and felt 
excluded from treatment planning. It is not surprising that some felt unable to act on the personal recovery plans developed in the team formulation. First, it is conceivable that as soon as participants left the formulation meeting, any first order changes that had occurred (e.g. invigorating sense of hope) were invalidated by the ward practices. Second, there may have been a lack of second order changes in the system, which are essential to lasting recovery. Indeed, some participants had little or no sense that acting on the formulation plan had occurred. Similar to the findings of Murphy et al. (2013), participants reported that wards were under-resourced, and that staff prioritised task-focussed activities.

The ways in which professional power is exercised within healthcare settings has been well documented. In particular, Nugus et al. (2010), in their study of acute and non-acute health services in Australia, found that professional power is applied along the following dimensions: decision-making, input into care delivery, the timing and topics of talk about care and evaluation of care delivery. The authors concluded that there is a continuation of a broad pattern of power by those in authority, which is shaped by the culture of the care setting.

Another factor was the timing of the team formulation. Five out of the eight service-users received formulation at the point of discharge from ward care. This automatically limited staff's ability to implement changes following formulation. The approach may be better placed earlier in the admission.

\section{Implications for practice and research}

Within the UK context, team formulation is receiving increasing attention as an organisational intervention aimed at improving the quality of care and outcomes for older people, and other client groups (Johnstone, 2018). This is concurrent with an urgent need to improve psychiatric care in a context of limited resources.

The application of the approach has been more limited outside of the UK, perhaps in part due to the lack of empirical evidence to support its use. We believe that team formulation has much to offer, but care must be taken to ensure that the process takes into account factors that could promote and limit the therapeutic value of team psychological formulation for older people with mental health problems and their carers. Such factors include the way in which the formulation is set up, who and how many people are involved, when it occurs, and how it is followed up. These practical recommendations link directly with the findings of this study, and are summarised in "Team formulation recommendations", using the mnemonic "SETUP".

Team formulation recommendations:

1. Service user/carer - invite them to the team formulation, develop a relationship and emotional connection with the process - pre-formulation meeting/conversation to explain the purpose of formulation and provide leaflet describing formulation, to orientate them to the psychological approach and develop rapport.

2. Environment - consider the emotional and physical setting and layout of the team formulation quiet and confidential meeting space; staff and service-user/carer arriving together; sitting in a circle/round table; everyone using similar furniture; everyone offered a similar drink.

3. Team - consider who is involved - small and relevant group: psychologist, service-user, carer and named nurse; the service-user/carer is involved in choosing who they wish to be involved.

4. Understanding - consider how each member understands their role and the role of others and how they contribute - introductions at start of meeting; staff trained in formulation and briefed about how they will contribute; service-user/carer empowered to recognise the value of their contribution.

5. Process - consider the process, timeliness and focus of the formulation - problem-focussed formulation facilitated with staff only early in service-users' recovery journey? Recoveryfocussed formulation facilitated with service-user/carer later in the recovery journey? Debrief at the end in private with the service-user/carer to explore and contain any difficult emotions evoked. Care coordinator to follow up session(s) to re-focus service-users/carers on their personal recovery plans, encourage and "cheerlead" engagement with plans and discuss 
barriers to behavioural change. Review formulation after period of time to implement

intervention plan with psychologist if necessary.

These recommendations have been used in the NHS Trust involved in this study, to inform service development. Delays in team formulation have been addressed. Preliminary findings from a service audit suggest that positive outcomes are related to: the therapeutic alliance developed through the team formulation; older people feeling able to contribute actively in team formulation; and feeling better understood.

IPA allowed for a detailed and nuanced investigation of the experience of a small number of participants. It is important to acknowledge the limitations of this approach. These include a neglect of the role that language plays in shaping experience, and a focus on description rather than explanation (Willig, 2001). Other qualitative methods, such as grounded theory, would have permitted a more explanatory and conceptual level of analysis. It is therefore important to note that it is difficult to fully generalise the findings of this study to other settings. Another limitation is that the study did not analyse in more detail the exact proportion of participants who reported negative vs positive experiences of team formulation. Whilst there are hypotheses regarding what participant-related factors may have influenced their views, these factors could have been more directly investigated.

Future research should focus further on the effectiveness of the problem focussed formulation model and the embedding of the SETUP recommendations in older people's services. Future research could also involve investigating the usefulness of the approach for older people with dementia. In addition, research should focus on the particular factors that could facilitate and act as barriers to team formulation outcomes, in both older people's services and more generally. More research into the effectiveness and outcomes of team formulation is also a priority. The focus on the views of the recipients of the approach, rather than the views of staff alone, is important and should continue in future research endeavours.

\section{References}

Baird, J., Hyslop, A., Macfie, M., Stocks, R. and Van der Kleij, T. (2017), "Clinical formulation: where it came from, what it is and why it matters", BJPsych Advances, Vol. 23 No. 2, pp. 95-103.

Berry, K., Haddock, G., Kellett, S., Awenat, Y., Szpak, K. and Barrowclough, C. (2017), "Understanding outcomes in a randomized controlled trial of a ward-based intervention on psychiatric inpatient wards: a qualitative analysis of staff and patient experiences", Journal of Clinical Psychology, Vol. 73 No. 10, pp. 1211-25.

Berry, K., Haddock, G., Kellett, S., Roberts, C., Drake, R. and Barrowclough, C. (2016), "Feasibility of a wardbased psychological intervention to improve staff and patient relationships in psychiatric rehabilitation settings", British Journal of Clinical Psychology, Vol. 55 No. 3, pp. 236-52.

British Psychological Society (2007), "New ways of working for applied psychologists in health and social care", Working Psychologically in Teams, British Psychological Society, Leicester.

Craven-Staines, S., Dexter-Smith, S. and Li, K. (2010), "Integrating psychological formulations into older people's services - three years on (part 3): staff perceptions of formulation meetings", PSIGE Newsletter, No. 112, pp. 16-22.

Crowe, M., Carlyle, D. and Farmar, R. (2008), "Clinical formulation for mental health nursing practice", Journal of Psychiatric and Mental Health Nursing, Vol. 15 No. 10, pp. 800-7.

Department of Health (2001), National Service Framework for Older People, Department of Health, London.

Department of Health (2005), Securing Better Mental Health for Older Adults, Department of Health, London.

Dexter-Smith, S. (2007), "Integrating formulations into inpatient services", PS/GE Newsletter, No. 97, pp. 38-42.

Dexter-Smith, S. (2010), "Integrating psychological formulations into older people's services - three years on (part 1)", PSIGE Newsletter, No. 112, pp. 8-11.

Division of Clinical Psychology (2010), The Core Purpose and Philosophy of the Profession, British Psychological Society, Leicester. 
Division of Clinical Psychology (2011), Good Practice Guidelines on the Use of Psychological Formulation, British Psychological Society, Leicester.

Geach, N., Moghaddam, N.G. and De Boos, D. (2018), "A systematic review of team formulation in clinical psychology practice: definition, implementation, and outcomes", Psychology and Psychotherapy: Theory, Research and Practice, Vol. 91 No. 2, pp. 186-215.

Godwin, B. and Poland, F. (2015), "Bedlam or bliss? Recognising the emotional self-experience of people with moderate to advanced dementia in residential and nursing care", Quality in Ageing and Older Adults, Vol. 16 No. 4, pp. 235-48.

Holmes, J. (2002), "Acute wards: problems and solutions: creating a psychotherapeutic culture in acute psychiatric wards", Psychiatric Bulletin, Vol. 26 No. 10, pp. 383-5.

Hughes, P.M. (2016), "Psychiatrists' use of formulation. Commentary on...psychiatrists' understanding and use of psychological formulation”, BJPsych Bulletin, Vol. 40 No. 4, pp. 217-19.

Johnstone, L. (2018), "Psychological formulation as an alternative to psychiatric diagnosis", Journal of Humanistic Psychology, Vol. 58 No. 1, pp. 30-46.

Johnstone, L. and Dallos, R. (2014), Formulation in Psychology and Psychotherapy: Making Sense of People's Problems, 2nd ed., Routledge, East Sussex.

Kerr, I.B., Dent-Brown, K. and Parry, G.D. (2007), "Psychotherapy and mental health teams", International Review of Psychiatry, Vol. 19 No. 1, pp. 63-80.

Kitwood, T. (1997), Dementia Reconsidered: The Person Comes First, Open University Press, Buckingham.

Larkin, M., Watts, S. and Clifton, E. (2006), "Giving voice and making sense in interpretative phenomenological analysis”, Qualitative Research in Psychology, Vol. 3 No. 2, pp. 102-20.

Leamy, M., Bird, V., Le Boutillier, C., Williams, J. and Slade, M. (2011), "Conceptual framework for personal recovery in mental health: systematic review and narrative synthesis", The British Journal of Psychiatry, Vol. 199 No. 6, pp. 445-52.

Maslow, A.H. (1943), "A theory of human motivation”, Psychological Review, Vol. 50 No. 4, pp. 370-96.

Mind (2011), Listening to Experience: An Independent Enquiry into Acute and Crisis Mental Health Care, Mind, London.

Mohtashemi, R., Stevens, J., Jackson, P.G. and Weatherhead, S. (2016), "Psychiatrists' understanding and use of psychological formulation: a qualitative exploration”, BJPsych Bulletin, Vol. 40 No. 4, pp. 212-16.

Moore, E. and Drennan, G. (2013), "Complex forensic case formulation in recovery-oriented services: some implications for routine practice”, Criminal Behaviour and Mental Health, Vol. 23 No. 4, pp. 230-40.

Murphy, S.A., Osborne, H. and Smith, I. (2013), "Psychological consultation in older adult inpatient settings: a qualitative investigation of the impact on staff's daily practice and the mechanisms of change", Ageing and Mental Health, Vol. 17 No. 4, pp. 441-8.

Nugus, P., Greenfield, D., Travaglia, J., Westbrook, J. and Brathwaite, J. (2010), "How and where clinicians exercise power: interprofessional relations in health care", Social Science and Medicine, Vol. 71 No. 5, pp. 898-909.

Onken, S.J., Craig, C.M., Ridgway, P., Ralph, R.O. and Cook, J.A. (2007), "An analysis of the definitions and elements of recovery: a review of the literature”, Psychiatric Rehabilitation Journal, Vol. 31 No. 1, pp. 9-22.

Pietkiewicz, I. and Smith, J.A. (2014), "A practical guide to using interpretative phenomenological analysis in qualitative research psychology", Psychological Journal, Vol. 20 No. 1, pp. 7-14.

Pinner, G., Hillam, J., Branton, T. and Ramakrishnan, A. (2011), "In-patient care for older people within mental health services: faculty report of the psychiatry of old age of the royal college of psychiatrists", available at: www.rcpsych.ac.uk/pdf/fr_oa_1_forweb.pdf (accessed 19 November 2018).

Rayner, K., Thompson, A.R. and Walsh, S. (2011), "Clients' experience of the process of change in cognitive analytic therapy", Psychology and Psychotherapy: Theory, Research and Practice, Vol. 84 No. 3, pp. 299-313.

Redhead, S., Johnstone, L. and Nightingale, J. (2015), "Clients' experiences of formulation in cognitive behaviour therapy", Psychology and Psychotherapy: Theory, Research and Practice, Vol. 88 No. 4, pp. 453-67.

Reid, K., Flowers, P. and Larkin, M. (2005), "Exploring lived experience”, The Psychologist, Vol. 18 No. 1, pp. 20-3. 
Schizophrenia Commission (2012), The Abandoned Illness: A Report from the Schizophrenia Commission, Rethink Mental Illness, London.

Shenton, A.K. (2004), "Strategies for ensuring trustworthiness in qualitative research projects", Education for Information, Vol. 22 No. 2, pp. 63-75.

Smith, J.A., Flowers, P. and Larkin, M. (2009), Interpretative Phenomenological Analysis: Theory, Method and Research, Sage, London.

Summers, A. (2006), "Psychological formulations in psychiatric care: staff views on their impact", Psychiatric Bulletin, Vol. 30 No. 9, pp. 341-3.

Tai, S., Kinderman, P., Choudray, S., Gillmer, B., Gwilliam, P., Hanna, J., Lavender, R.H.T., Pilgrim, D., Shepherd, G., Taylor, J. and Taylor, J. (2009), "Psychological health and well-being: a new ethos and a new service structure for mental health", A report of the Working Group on Psychological Health and Well-Being, British Psychological Society, Leicester.

Taylor, K. and Sambrook, S. (2012), "CBT for culture change: formulating teams to improve patient care", Behavioural and Cognitive Psychotherapy, Vol. 40 No. 4, pp. 496-503.

Willig, C. (2001), Introducing Qualitative Research in Psychology, Open University Press, Maidenhead.

Yardley, L. (2000), "Dilemmas in qualitative health research", Psychology and Health, Vol. 15 No. 2, pp. 215-28.

\section{Corresponding author}

S.J. Summers can be contacted at: A.Summers@tees.ac.uk

For instructions on how to order reprints of this article, please visit our website:

www.emeraldgrouppublishing.com/licensing/reprints.htm

Or contact us for further details: permissions@emeraldinsight.com 